\title{
Upbringing, Mathematics and the Sign Over the Door of Plato's Academy: On the Beginnings of Self-Formation
}

\author{
Alan Blum and Peter McHugh \\ York University
}

\section{Introduction}

Our topic is the good upbringing. The topic directs us to examine the relationship between the family and the outside world insofar as the family seeks to prepare the child for that world. One version of the good upbringing is that it prepares the child well.

What is a well-prepared child? Is it the child who excels in the skills thought to be required for behaving adequately in the world? And what about good behaviour? Is this reflected in the child's ability to fulfill the expectations and requirements which are established for him by adults? If so, the good upbringing would be the one which equips the child with skills that enable him to fulfill expectations. But there is a tension here: can we not imagine the upbringing which strengthens the child to the point where he does more than satisfy expectations, actually contributing to a redefinition of the expectable? Or do we want to assume that the well-prepared child is one who takes for granted the good of expectations without respect for their quality? We can certainly imagine the child who questions the quality of expectations: what does an upbringing have to do to prepare such a child? And does an interest in examining the good of expectation show a desire to replace conventions or to moderate their acceptance?

Typically, the idea of a good upbringing has been identified with the preparation that leads (or lends itself) to the acquisition of skill. While the deep character of skill has been left unformulated in these conventional versions, it has been assumed as the type of self-mastery that is reflected in ideas such as mobility vis-à-vis father's occupation, psychological "well being" such as independence and autonomy, and the cultivation of certain types of abilities. We might certainly question whether the type of ability reflected in these behaviors points to the notion of self-governance.

In these versions upbringing is equated with technical resourcefulness; the cultivation of excellence, which is an element intrinsic to the idea of an upbringing, is abandoned. That is to say that self-governance needs to reflect more than the type of ability, talent or facility that assumes whatever it excels at as excellent because governance is the exercise of authority that organizes resources in the service of an end the quality of which is deliberated upon as an end that is worth serving. Without further theoretic elaboration pure resourcefulness is only efficacious and so, indifferent to value unless the end towards which it is directed is included as a necessary and desirable matter of concern for its own development. When upbringing is equated with competence, the capacity to address quality and to question the authority of those who repute quality to be as it is is not treated as a problem for the child to master.

For example, the occupancy of a particular job is created by a multis of social structural conditions and never is in-itself responsive to the question of how well the work is done. Unless it is assumed that occupancy exemplifies quality, we can only say of such an upbringing that it prepares 
its offspring to take advantage of opportunities so as to elicit from others the recognition that it is qualified.

Yet the question we are concerned with is the difference between what is reputed to be qualification and what is genuine qualification. Deeply, this question presupposes an examination of those who repute qualification to be as they say, an examination of their authority. So a good upbringing can not merely satisfy expectations because these expectations could be established by lunatics or idiots.

\section{Upbringing and the Examination of Opinions}

The good upbringing must then, prepare its young to distinguish between genuine and counterfeit authority; the eagerness of the young to fulfill the expectations of those who repute qualification to be as it is must be mediated by a deliberation upon the question of quality as a question that is not merely presupposed in images of competence and mobility. This is to say that if the good upbringing establishes an appetite for self-governance, the conception of self-mastery reflected in these versions of development does not necessarily reflect the capacity to govern oneself in the strongest sense.

If it is inferred from this that the good upbringing prepares children for "critical thinking," this is still too facile; any kind of critical thinking is itself prepared by the need to assess quality or value. The good upbringing produces first a desire to deliberate upon quality in the form of a desire for guidance in the conduct of this deliberation.

Another way of saying this is that the young must be prepared to examine what they are told. This means that they must examine the relationship between skill and quality. This examination takes the form of a recognition of their need to formulate what they are told as an order to which they orient, i.e., as an order that is positive and desirable.

The young, then, need more than skill in order to deliberate upon this question. They need to be told and to be shown how to examine what they are told in order to determine if what is reputed to be, is. This is to say that the young need to examine the authority of those to whom they are exposed. But to examine that authority they first have to accept the authority of those who can lead them in this examination. If the acceptance of this authority is instinctive, such instincts must be prepared in the family. This is the instinct to submission which Rousseau noted.

However, the authority of the family cannot itself first be questioned because the child's initial lack of qualification makes him dependent upon the family's authority in order to develop the ability to examine authority itself. Here, we begin to glimpse the good upbringing as one which actually uses its force to develop the child's ability to examine authority in a way that could risk putting into question the very authority of the family. This means that the child needs to depend upon familial authority to learn to put authority into question: in this sense, he does not put the authority of the family into question. The family invites him to accept its own force not because parents are a dogmatic and self-interested ruling class but because his learning to question absolutely depends upon his ability to let some 
matters stand fast, i.e., to accept and find pleasant, limitation. The family is then confident that his development of strength will eventually strengthen them for it will lead to his ability to influence them to reexamine and reevaluate their own authority. The point is that the unqualified child needs to depend upon their authority in order to eventually develop the strength to exercise his own authority in a way which will include the putting of parental authority into question in a positive and influential way.

If developmentalism treats the good upbringing as the acquisition of perspective which results in the renunciation of frustration, we are interested in the work that is necessary to remind the child that it is both necessary and desirable to transform frustration. The frustration of underdevelopment can only be transformed when development is seen as incidental to childhood and so, when the limitation expressed in the notion of childhood is oriented to as a standard of self-governance rather than as an obstacle to be overcome or mastered.

The pleasure of childhood depends, then, not upon mastering the problem of development in the sense of freeing oneself from dependency because it is through the experience of dependency that the notion of childhood comes to express itself. Rather dependency must be oriented to and governed by a sense of its necessary and desirable character. That the child ought to act from necessity means that he needs to enjoy dependency and not seek to reduce it.

To govern oneself is to address one's needs under the auspices of the question "What is necessary?" when this question is heard as asking "What is necessary because it is desirable and what is desirable because it is necessary?" One who exercises self-governance addresses the difference between basic and true needs, between needs which must be satisfied because they are conditional (the need to "develop") and needs whose necessity is based upon this desirability (value) in-itself (e.g., the need to see the difference between what is incidental and what is essential).

The good upbringing begins to orient to its true rather than apparent understanding of dependency. Dependancy is treated as what is essential to childhood and so is a limit rather than a condition. As a limit dependency raises not a developmental problem requiring self-mastery because it indirectly poses the issue of self-governance, of the need to orient to necessity and desirability in a way which expresses unqualifiedness.

\section{The Pleasure of Learning}

We say that the family prepares the child to find learning pleasant initself. In self-mastery we say that the child wants to be unlike what he is leaving behind (dependency, powerlessness, incompetence) more than he wants to be what he is striving for. Self mastery is not yet expressed as the pleasure of learning in-itself because it is aroused by the deprivation of powerlessness; at best it is pleasure only by implication, at worst it identifies pleasure with the exercise of skill.

We see the limits of skill in the example of a child who learns to exercise his ability through swimming. Regardless of his confidence such a child 
never truly masters the water insofar as mastery is essentially limitedthere is something other than the exercise of skill through which he embodies his confidence. What the good upbringing teaches the child who learns to swim is that skill itself is limited: it is limited not only by the power of water, by water's alterity, by water's resistance to mastery, it is limited by itself. In this sense self-mastery as a commitment does not provide for a strong sense of otherness as a necessity for the very idea of mastery without which mastery would be a vacuous interest. Other thus refers to the limitations of development rather than to the recalcitrance of nature which mastery overcomes in the learning of a skill.

In a certain respect, the idea of self-mastery reproduces the structure of authority as that interest was discussed in Plato's Republic. This is because the interest in mathematics is directed to order without respect to value.

If mathematics exemplifies self-mastery it is strictly speaking indifferent to the need to integrate its own development with the development of the notion (of language) i.e., the well ordered soul is necessary because it frees one to exhibit one's distinctiveness but does not yet show a need to submit to the discipline of self-governance. Eventually we will demonstrate how the orderliness of mathematics idealizes the possible as the necessary without respect to the value of what is possible. In contrast dialectic references the recognition of the need to govern the understanding that was achieved through the contradiction as released by what we will examine below as the mathematical. Self governance occurs insofar as the well ordered soul needs to achieve and reachieve itself through discourse and its work of developing what the notion implicitly and essentially is in a way which discriminates the essential character of the notion from what is incidental to it.

\section{Achievement as Compensation}

In contrast to this conception of the good upbringing which is presaged in the Greek notion of Paideia as cultivation for excellence and so, as something more than "socialization" and "education," we have those received versions of childhood that treat the well-prepared child as one who is motivated to fulfill expectations.

For example, there is a literature which speaks of the family's influence upon the child's "achievement." When examined closely that literature can be seen to accommodate a conception that is indifferent to excellence. For example, in some studies the son is said to excel as a competitive person because he is motivated by his attachment to his mother to seek to replace his father. In other cases, his behaviour is said to result from his desire to please both parents by satisfying their expectations and since it is assumed that he needs to respect those he seeks to please, the good upbringing is said to teach respect for parents. Note though, that in order for such "respect" to be a condition of achievement, those who show it must be assumed to orient to the parental standard as worth emulating. Yet when influence is segregated from excellence, any condition that compels the child's striving is treated as a good influence (imagine the child's "mobil- 
ity" which derives from his destructiveness and his hatred towards his family) and then the bad upbringing would be confused with the good.

To put it otherwise, a good upbringing cannot be one that teaches the child either to affirm or deny parental authority where such an action is formulated as treating this authority as a limit. The good upbringing does not say: the one who does as he does is caused to do so by family, he does it because of family. Instead, the good upbringing teaches how conditions that could operate as causes need to be reformulated before they are influential: the need to reformulate conditions through a deliberation upon their desirability is what mediates the family's effect upon the child.

In this sense the literature views the good upbringing as the conditions which compel or cause the child to act in an approved way. In contrast, we understand the good upbringing as needing to arouse the child's interest to desire influence and so to deliberate upon conditions in order to determine their quality.

The interaction between offspring and parent is sometimes thought to be an instance of Desire, but only when we understand Desire interactionally, as an aspiration to replenish or attain what is lacking. In this sense the object of Desire is wanted not because of its intrinsic excellence but for the reason that the one who seeks to attain it lacks it. Excellence is not intrinsically attached to the object because the subject's action is grounded in an experience of the inequity or privation for which the object's attainment is designed to compensate.

Desire here is anchored in the aspiration to be other than we are or to be as we are not. What interaction shows we are not but can desire to be is the parent: in this sense the relation between offspring and parent is a relation between subject and mediator. ${ }^{1}$ The offspring's desire to be other is mediated by the parent who exemplifies the qualities which the offspring wants to achieve and of which he is deprived.

As such a mediator, the value of the parent is given by the accident of his typifying whatever the offspring lacks. The value of the parent is grounded in the weakness of the offspring. If the offspring wants to be other than he is, i.e., to be powerful, and if the parent only exemplifies power by virtue of being what the child is not, this says nothing about the value of the parent's power.

Apparently, the power of the parent is grounded only in his having developed what is underdeveloped in the child. The difference between offspring and parent is then inessential and accidental even insofar as the child orients to it as fundamental and as a limit upon his horizon. The best the child can imagine is the unimaginative and particular opposite of what he is, the parent.

This interactional version of Desire recommends that aspiration toward the other only occurs by producing hatred towards the self as one who lacks what the other possesses, whereas a strong notion of Desire would preserve the relation between self and other. A strong version would say that what is desired is always in some sense present in the subject who desires, only needing to be worked out and made explicit as part of his de- 
velopment. In contrast, in this version one not only hates one's self for lacking what is wanted, but he hates what he wants because his lack of it is an obstacle to what he wants to be.

What the interactional notion of Desire releases in the subject, then, is his hatred for being determined (for his own finitude and limitation) and hence, an essential enmity toward his status as a part of the whole rather than as the whole, itself.

The good upbringing needs, then, to produce in the child reserve toward the difference between his self and the parent as other because such a difference is inessential vis-à-vis the difference between man (any man) and the whole. The child is invited to understand the difference between man and the whole rather than to seek to reconcile the difference between what he lacks and the other man has.

We might ask, though, how the child is to understand his difference from the parent in a strong way? We say: what the parent has and the child lacks and seeks to attain is the skill which they both need him to attain. This is not a zero-sum game since the parent helps the child attain the skill he lacks in order to understand that what he (they) deeply need(s) is other than skill (and so, other than what either or both of them possess).

We say, then, that the good upbringing needs to lay the ground for the child's capacity to be pleased, to experience pleasure, and the conventional picture of the good upbringing as the one that leads to achievement tends to equate pleasure with the removal of pain. In contrast, the object of desire (other) must be good in-itself and not because it replenishes what is painfully lacking. Another way of saying this is that the pain of the child must not be the pain of deprivation or inequity (which is only the pain of being powerless in a social structural sense) but should instead express the perturbation of his harboring discordant or unwelcome propensities in the soul. Pleasure is desired insofar as it harmonizes the elements of the soul and not because it obtains what is lacking. The soul is a mixed company wherein the pleasing and the painful co-exist and so the desire for the pleasing is not the desire to obtain what is lacking but to reestablish a good relationship among these elements. The object of Desire is the pleasing harmony between pleasure and pain in the soul, and so it is the harmony per se and in-itself.

\section{The First Move Towards Mastery}

Ground is prepared when the child is directed to find harmony pleasing and disharmony painful and he will want to achieve the pleasure of harmony over the pain and dispersion of discordance. Yet, harmony is not an external which is "other" to his current state, for it expresses the developed and explicit form of the relationship between elements that are implicit in his soul. The desire for harmony as pleasure is the desire to work out and develop this relationship as a way of reducing discordance. This distinction is perhaps first clearly prepared in Plato's Republic.

The story goes that Plato inscribed over the entrance to his academy the words "let no one who has not grasped the mathematical enter here!" 
Assume the academy to stand for the good school or the school which personifies an interest in the excellence of its "subject matter" which is education. The question is, "What does the good school need from its students?"

We say that the answer-"mathematics" - can be heard in this way: that the good school needs its students to have been prepared with a good upbringing. To say "mathematics" is to say that education needs its students to have a good upbringing, it is to say that school needs its students to come from a good family. Mathematics references or signals the notion of an upbringing and not "geometry" or "calculus" (or skill or accounting or even Sesame Street).

What we must do is demonstrate the cogency of our stipulation. That is, we need to demonstrate how the sign requires of the student a good upbringing and we proceed by developing a conversation on how "mathematics" can be heard to reference the notion of an upbringing.

The sign alerts us to the way in which we begin to think about the notion of an upbringing, to the way in which we could anticipate an upbringing to prepare its offspring for the academy.

This requires us to ask after the value of "mathematics" such that an upbringing can cultivate its grasp. If we do not require of the family that it train its offspring in geometry, what do we require when we demand of it preparation in mathematics?

For a start we propose that we take as text some part of the talk of Socrates where he speaks first about "mathematics" and then about the idea of an upbringing. A consideration of the relation of mathematics to upbringing will begin to situate our problem by making transparent the direction for an analysis,

So we may conclude that a soldier must know how to count and calculate?

Does it strike you that this study is one of those that we are looking for, which naturally awaken the power of thought, though no one makes a right use of its tendencies to draw us towards reality?

Take our perceptions then. I can point to some of those which do not provoke thought to reflect upon them, because we are satisfied with judgement of the senses. But in other cases perception seems to yield no trustworthy results and reflection is instantly demanded.

You mean objects seen from a great distance or illusory effects in scene paintings?

No, you have not understood me. I mean that reflection is provoked when perception yields a contradictory impression, presenting two opposite qualities with equal clearness, no matter whether the object be distant or close at hand. When there is no such contradiction we are not encouraged to reflect. ${ }^{2}$

The problem resides in what youth needs. According to Socrates, what is needed is to "awaken youth" to the power of thought. What this means is that its thought needs to be provoked to reflect upon its perceptions.

Provocation introduces the idea that the move to self-reflection is not evolutionary or inevitable insofar as the tendency of thought to be "satisfied with judgements of the senses" needs to be arrested. Socrates does not imagine a world of continuous re-iterated provocation-a world in which 
nothing is held fast and agreed upon-for he suggests that we often have good grounds for standing fast on our judgement.

In fact, Wittgenstein would say that, strictly speaking, it is nonsense to talk of grounds for holding fast because our life requires of us that we disregard the temptation to continuously question our judgements. ${ }^{3}$ In this sense, Socrates is not different than Wittgenstein, we must learn to reflect upon our perceptions but not in the way of cynical immoralism. What we acquire is an appetite or desire to reflect upon judgements for we tend to be satisfied with the judgements of our senses. Strictly speaking what we learn is not to be endlessly dissatisfied but to question our satisfactions: because our doubt needs to be oriented we are not to question all of our agreements, but rather we question the difference between complacency and satisfaction. When we say that we learn to treat our satisfactions as a problem we do not mean that we learn to become quickly dissatisfied, but that we learn to ask questions of our satisfactions. How does an upbringing teach us to question our satisfactions? As a start we say it teaches us in the same way that it teaches us to question anything: by leading us to ask about our satisfaction for example, "Is it apparent or real?"

What has to be learned is the way in which our satisfactions need to be scrutinized. That we are satisfied with the judgements of our senses means that we have no good reason to doubt such judgements.

This means that we need to be aroused, provoked or inspired to doubt the judgements of our senses. Actually, "inspiration" best captures the positive sense of this move, for at the root of our questioning lies the desire to put into doubt our satisfactions not just because whatever satisfies us is disturbing but because reflecting upon our satisfactions is good, is good initself.

Now Socrates suggests that youth is unqualified in this sense: that youth is not prepared to treat reflection as good in-itself but must be provoked or aroused to reflect. Youth must be compelled to reflect through the contradictions presented by an impression. In this sense we say that youth as compared to maturity, needs to be stimulated.

This is interesting for there are various versions of self-reflection that make its origin contingent upon the recognition of some contradiction. But Socrates is speaking about youth who are unqualified: presumably the mature, wide-awake theorist (like Socrates) covets self-reflection as a need or passion (Hegel says, Desire) independently of external conditions. Socrates' craves to reflect upon judgements because the oracle told him that the incorrigible difference between what appears to be and what is (between what judgement judges and what reflection knows) is a difference that language makes continuously questionable. So Socrates does not now need provocation although to be free of that need he had to pass through the period of mathematics (the period when we are compelled by contradiction to reflect).

That the mature theorist is not compelled by contradiction to reflect means that he is inspired by the difference between what is and what appears to be as that difference is given in language. That difference is not a contradiction for it shows the positive and essential character of what language is. 
On the other hand, youth has to be compelled to reflect. That youth needs to be compelled by contradiction means that it is in some sense going against the grain to reflect or to question our judgements of sense. Our judgements of sense are satisfying. We go against the grain, then, when we have to doubt what gives us satisfaction.

Now, for Socrates, to doubt our judgements-to reflect-is itself satisfying. The problem with youth then is that it does not find self-reflection satisfying. For youth, other versions of satisfaction take precedence.

Mathematics is a way of referencing what the good upbringing must know and do: Socrates says that its study can awaken the power of thought if "a right use is made of its tendency to draw us towards reality." The good upbringing must make right use of the study of mathematics in order to prepare youth for the school. The good upbringing is one which orients to the uses of mathematics as such a method.

Youth is satisfied with its judgements, even as it may adjust and revise them in specific instances. It is not particular judgements that need to be questioned, for what must be acquired is the notion that judgements can be questioned. Youth must come to see that satisfactions can be disturbed under the auspices of a desire for a higher type of satisfaction. The satisfaction gained from questioning judgements is higher than the satisfaction realized in accepting our judgements of sense. That this satisfaction can be gained means that there is something other than the satisfaction which comes from perception.

Socrates is then laying the ground for a critique of pleasure insofar as he says that the satisfaction which we obtain from accepting our judgements is not as great as the satisfaction of reflection. If we do not find what we must do truly pleasant then we will only endure it as an obligation. What is pleasant and what is right will be segregated as in the life that splits enjoyment from work, satisfaction from reflection. Of course, youth can be forced to reflect but it will not enjoy it because it will not treat reflection as intrinsically satisfying-it would only be a lack to remedy-and so youth must be prepared to see that self-reflection is satisfying in-itself, that it is a true rather than apparent pleasure.

\section{The Appetite of Youth}

The need for mathematics then says: youth must be led to see the difference between apparent and real satisfaction. Mathematics provokes youth to glimpse this difference in the sense that youth needs to be led to desire as an image of true satisfaction questing after the difference between true and apparent satisfaction.

Imagine the situation of one who is satisfied with his judgements of sense. This seems to mean that he desires nothing other than what is revealed in the certainty of the judgement. He has no need for anything other. In some respect, mathematics introduces the appetite for something other than what the judgement gives (we are preparing here to narrate a history of the soul as the stages through which our desire for Other is aroused and developed). 
Socrates says that in the beginning for the unformed soul, contradiction is required. At first one primitive version of contradiction describes the disturbance occasioned when the child's satisfaction with his judgement is questioned by showing him how his satisfaction depends upon external conditions. He comes to understand that however secure his satisfactions are they are always vulnerable to frustration, so that their attainment is always contingent. How can one be truly satisfied with that which is variable and unstable? The child is then provoked to glimpse the need to understand true satisfaction as something stable rather than variable.

In the beginning we might say that what gives the child satisfaction is his ability to satisfy others. His desire for satisfaction is mediated by his ability (his skill) to satisfy others who then provide him with what he requires. The so-called dependency of the child means that his satisfactions are only realized through the intervention of the others and so what deeply pleases him is his ability to persuade the others to provide such satisfaction. We might say that what satisfies the child are his own abilities and that his satisfaction varies depending upon whether or not he can exercise his skill successfully. This is the period of self-mastery, and when he recognizes the need to master dependency as his limit.

The child is satisfied when what he lacks is replenished by what he wants: he wants what will replenish what he lacks. We say then that what satisfies him is apparently pleasing since replenishment only fulfills us by providing what is lacking (according to Socrates, it is like scratching which relieves the itch, which is not pleasing in-itself).

This stage we might think of as the stage before the mathematical. Contradiction is understood primitively as the offspring's need for replenishment, which is mediated by his ability to comply with the requirements of external conditions, so as to influence these conditions to supply him with what he lacks.

What gives satisfaction at this point is the attainment of what is lacking and so, what is wanted as satisfying is not satisfying in-itself but only because its lack causes distress. The value of satisfaction originates in the distress of need and Socrates said that what satisfies in this way is apparently satisfying, it is satisfying only by implication.

At this stage the child is not truly contradicted but only frustrated. In contrast, mathematics contradicts but does not frustrate because in showing the limits of the familiar it arouses his appetite for something other, whereas frustration simply shows agitation, and is ruled by the limit of powerlessness.

This is essential: Socrates hints that it is only when we are free of the circle of pain and satisfaction as want and replenishment that we will be ready to experience pleasure in-itself. What pleases us has to be pleasing in-itself and so, it has to be more than what relieves our distress or reduces our pain. The child must be led to take replenishment for granted in order to find what he wants pleasing in-itself. This begins to point to the domain of the mathematical. 
Mathematics arises in response to the need to integrate the wants of child and others. That is, the child is required to understand that the contingency of his satisfaction upon the satisfactions of others is not, strictly speaking, an interaction. It is not that he wants what he lacks and what they can provide but that they both want the same. That is, if he is pleased when he pleases them, he needs to imagine that what pleases them is good. That the child satisfies himself in pleasing the others means that he desires to please the others as his way of satisfying himself. Mathematics begins to point for the need for order embodied in the unity of our wanting and being pleased by what we need.

Before mathematics we want what we do not have and need merely because we do not have it: our need for what we do not have is really primitive, it is necessary for survival but it is not a true necessity.

Mathematics exposes us to the need to endure what we appear to need with more than survival value, with a sense of rightness.

In this sense the pain which mathematics causes us is more of an incentive than a limitation. Mathematics induces us to suffer the recognition of the limits of judgements of sense as a way of glimpsing how the need for security resides in some recognition of limits that are not constrained by context. Mathematics exposes us to the need for self-governance in the form of our recognition that our pleasure in exercising our abilities will only be true when it is guided by some conception of the end which such exercise serves.

The family desires for the child that he take pleasure in satisfying expectations. The family takes pleasure in a child who is not only motivated to relieve distress but who finds his agreement with expectations pleasing in-itself. The child must see that he needs for himself what the family needs for him: this requires seeing the family as wanting the best for him, which is also the best for them. This need introduces the idea of what is right into his development.

Mathematics now references the child's need to find pleasing intrinsically and essentially the requirements which he previously endured and so it points to the instability of a life of replenishment-of distress and fulfillment-that is not mediated by belief in the good of what is expected.

\section{Mathematics, Contradiction and the Story}

The contradiction is experienced in whatever child-rearing practices expose the relation between what is apparent and what is real as itself a problem for the child. These are the practices when appearance per se insinuates itself into the life of the child, in which splits, doubles, guises, semblances, partitions, and the like arise in the course of his satisfactions.

Historically, the problem is introduced at the mirror, where the double that is seen does not simply confirm in its appearance that one is real, nor that the double is merely one among many appearances. Just another confirmation or one more appearance, would be repetitions of satisfaction-dissatisfaction insofar as they would not stir any interest in the nature of appearance itself. Rather, the mirror provokes consideration of whether there is a place for what is real in what appears, whether we are as ephem- 
eral as the appearance, now seen, now not, in the mirror. Certainly the child is satisfied to make an appearance, but not so satisfied that the double does not induce wonder about this satisfaction, i.e., whether the appearance is original-is him-and thus a reflection. In this sense, the appearance comes to be understood as a reflection (which has not been the case for satisfaction) and thus is not itself true except as it reflects the real, except as it is a reflection. The appearance is then indirect, even as it is seen to be a copy-in-the-mirror, because it is both what it is (an appearance) as well as a manifestation (of the child). What is contradicted here is any direct or assimilative or mechanically reproduced relation between what is real and what appears (between the satisfaction and what the satisfaction exemplifies) because that relation is always a problem. It only expresses itself through reflection, reflection now intended in both the mirror and self-reflective senses of the term. This is to say that the appearance of the reflection can only be understood as a reflection by reflecting upon what it is that is reflected.

What is contradicted is any uniform determination of the relation between the appearance and the real as that which the appearance manifests. What is not contradicted is the possibility of something other than a uniform relation between appearance and the real, e.g., that they may supplement one another, subvert one another, and so on. What is not contradicted is thus that the one may contradict the other. The one real child may be embodied in many appearances, some satisfying, some not; that some of these appearances are satisfying would mean that they are satisfactory to him as appearances of him. The mirror stimulates the child to imagine the nature of exemplification as the problem of the relation of what appears to what is real. What appears and what is real are both necessary, both desirable, yet each is different.

Children's need to be satisfied often comes alive in story-telling. They like the story: its characters, the drama, what the story is about. In the same way they like to hear the story: the engagement with a parent or teacher, the story as part of their lives, the setting in which the story is told and retold. The story is about something, and it is told somewhere. Being told something is usually satisfying to a child when it is known to be fictive, and to find that there is a place for this only amplifies the gratification. Children love the usage of the story, the appearance in one embodiment of tale and setting where the interest in the who-did-what of the tale is matched by the who-did-what of the family - no double, no reflection, no problem. All is satisfaction.

But of course it happens, and not accidentally, that the story will gain a life of its own. It is not simply about its characters; nor is it about its setting, a parent or teacher. Rather, it is something: it is told, it narrates itself, it is substantial. The story does not expend itself, as news does, because it is not a report of events external to itself. It is not a fact, not information "about" an event, not an oral replication, not a message-it does not need these because it is not an agent of competence.

This means the story has its own needs, and that means it is real, that it is more than the identities of its characters or the variable occasions on which it is told. The story is not just satisfaction. The reality of the story is 
that it is an appearance. And so it raises again the problem of the mirror: what is appearance?

The story approaches the relation between apparent and real as, in the story, the way that satisfaction is an appearance. It asks: of what is my satisfaction a reflection? It asks what is real in the appearance of satisfaction in the story.

In other words, the story begins as a double of the child's satisfactions -it is no more than a replication of these, much in the way the first news of a good thing is satisfying to an adult. The first news is expendable, however, because it is the good thing in which we're interested; and unless the adult is childish, the good thing must somehow be thought a reflection of him and thus a real appearance. This is to say that the story interests the child in what a good thing is by moving him from being satisfied by the story to a recognition that satisfactions are an appearance (of him) and hence may or may not embody what he is. We might say that stories give the appearance of satisfaction, i.e., they simultaneously satisfy the child and satisfy the need for appearance.

The story approaches the relation between apparent and real through its development of the relation between satisfaction and appearance. The child begins in dependency and want, which are relieved or satisfied by the telling of the story. That he begins in dependency means he relies on the parent to satisfy him, and he knows this. The parent is powerful because the parent has the power to satisfy or not to satisfy. As the story is told, that the power to satisfy is not withheld expresses to the child an interest of the teller in satisfaction which is not dependent on want since power here is the power to satisfy oneself, for example in not telling the story. An interest is expressed in the telling, an interest that has begun to be differentiated from satisfaction of want in the sense that the teller or parent has the power to satisfy himself and thus is not dependent on the way the child is.

So it is the child's very dependency-his want, his lack of power to satisfy-which initiates the possibility for him of something other than sheer want as an interest. For the parent to give satisfaction out of something other than compulsion or lack confers the appearance of an interest in giving satisfaction, even if only an interest in gaining satisfaction out of having given it. The parent now may be thought by the child to enjoy (the appearance of) his interest in the child as one which will give him pleasure through the telling of the story. The teller is in the story for the child-the teller makes this appearance-in that the teller narrates his own interest in satisfaction in the telling of the story as he tells it. His narration of this interest means that he appears in the story, appears in the satisfactions given and received. This is what makes the story something in-itself and not just an expendable for the child: it is the appearance of an interest, the place where appearance and not just satisfaction appears.

As the appearance of appearance is accomplished in the story, the primitive double of the child by the story is moved toward the partition of satisfaction from appearance: through the appearance of the parent's own interest (this is not to say he must like the story concretely) the child learns 
that the interest may or may not be restricted to giving him satisfaction, that the parent's interest may not be a double of his. And so, one way or another, the child asks: "What is the particular interest that appears now in the telling of the story, since it may not be identical to satisfaction?" At this point the child grasps that satisfaction and appearance, though they can be complementary, are wholly different. ${ }^{4}$ Once he had asked of the parent (story): "What satisfaction will you give me?" Now: "What is it that you are that gives me satisfaction?" In sum, the appearance of satisfied power in the story tells the child that qualified satisfaction is an appearance. As an appearance it ignites the question of whether it is real.

The story, then, exemplifies how all depend upon a way of bringing their relation to appearance and marks the point at which the congeries of structural accidents with which upbringing must begin can become more like a family than a service station. Now all can seek the satisfaction of the appearance of, say, "speaking togèther" through the story. That they all would seek the satisfaction of speaking together means they need to embody or concert upon reflections of their relation, that the satisfaction is an expression of a need which is real, a family and not bundles of satisfactions. For the child the story is a name for the appearance of appearance as a real need. He learns he can be pleased when satisfaction appears as a true need. The regulated excitement and order of this-the true nature of satisfaction itself as an appearance and not just a double-is lived through countless retellings of the story which would otherwise be utterly soporific. The satisfaction of speaking together is thus an instance of the collectibility of satisfaction, is an appearance of the real. The story is a good example of this relation as a problem worth considering, because it brings to appearance as a satisfaction the need and desirability of such a relation, while at the same time it is a satisfactory embodiment of that relation for the child.

Thus, the contradiction as expressed through the story does not expose an absence or lack, even as it begins with that, but rather: (1) The good problem of the relation between what appears (the satisfaction of the story) and what is real (that what is real, e.g., the family, must appear); (2) The good problem of the appearance of satisfaction (the story being told) with that which gives satisfaction (here, the nature of the story). The story provokes the child to consider what is exemplified in appearance in precisely the same way as our simpler story of the mirror provoked us to see the need for contradiction in a good upbringing. The story contradicts unqualified satisfaction in the very course of providing it, and thus prepares the child to enjoy the examination of his satisfactions.

Mathematics then says-how can your judgement of what is satisfying be right judgement unless it is governed by a belief in the rightness of the expectation which you desire to satisfy? Mathematics introduces the notion of right judgement and the sign reads: only those who have recognized the need to judge that which gives them satisfaction is right, should enter the school.

\section{Being Acted Upon}

In the Republic while speaking of the education of the guardians (the youth), Socrates addresses the importance of music, 
Rhythm and harmony seek deep into the recesses of the soul and take the strongest hold there, bringing that grace of body and mind which is only to be found in one who is brought up in the right way. Moreover, a proper training in this kind makes a man quick to perceive any defect or ugliness in art or nature. Such deformity will rightly disgust him. Approaching all that is lovely, he will welcome it home unto his soul and, nourished thereby, grow into a man of noble spirit.

Since Socrates is speaking about a perfect state, the "upbringing" that is so described exists nowhere. What does exist everywhere as an essential part of man is that he is a result of "upbringing"; that man is educated allows us to see in any man his "upbringing." It is just as necessary that his upbringing not be the "right upbringing," for if the perfect state exists nowhere, the nature and kind of rhythm and harmony which penetrates into the soul will vary. What takes root in "the recesses of the soul" will be a chance effect. In the perfect state this ought not be the case, but in our states, our souls are rooted in harmonies and rhythms that are indifferent to value.

Each man then, as he recollects his childhood understands his roots as the hold which rhythm and harmony has taken in his soul. While we ought (be educated) to be hospitable to beauty and repulsed by ugliness, at the root of our souls beauty and ugliness coexist as equal temptations.

Our upbringing then displays the way in which our society communicated to us its initial experience of us and so in every case it shows how our soul mixes images of both true and false pleasures. That our roots are a mixture of these temptations only means that the music which has penetrated and has taken hold of our soul at its deepest recesses is a music that can charm us to be hospitable to ugliness and to be repulsed by beauty. One of our temptations is to forget that we have been educated by pretending that we come from the perfect state where what we need to recall is our root in accident and so to re-collect what is worth preserving.

Upbringing refers to the problem of the writing which takes hold upon the soul, the writing which is inscribed upon the soul. The unqualifiedness of the child refers to the openness and the innocence of the soul that is vulnerable to such a writing.

In The Republic, Socrates identifies music as the primordial writing, as the first method of inscribing influence upon the soul. To raise a child is to seek to inscribe upon his soul images which he can covet and seek to attain and sustain in contrast to images which he will find repulsive and seek to repel. The metaphor is bodily, as if what is inscribed is instinctual, permanently embodied as an appetite and aversion.

The first writing inscribed upon the soul is music in the sense that this writing establishes the appetite for harmony and rhythm. If harmony and rhythm are icons of order, we see that the first writing upon the soul ought to establish a need to be hospitable to order (beauty) and repulsed by disorder (ugliness). What the first writing does establish is a position (a propensity, an instinct) in relation to the need for order and disorder.

If the first writing establishes the co-existence of beauty and ugliness, the child must be invited to find beauty (order) pleasing and ugliness (disorder) painful. What is established as part of the first writing is the need 
for the child to orient to the relation between beauty (order) and ugliness (disorder) in a way that is strong. The child cannot avoid exposure to both order and disorder. Social structure is indifferent to the quality of the exposure. Important is that an appetite be established in the face of such indifferent conditions. What the first writing establishes, then, is a need to discriminate, because only through discrimination can orderliness be retained and disorder expelled. Order (harmony and rhythm) must be found pleasing in itself. What is prepared in the offspring is a need to find a wellordered soul pleasing; the child must orient to the pleasure of the wellordered soul; then, he will work to expel disorder and achieve harmony.

Socrates says that what takes strongest hold in our soul (music) produces an "elegance" or "grace." Music invades the senses and takes the strongest hold "in the recesses of the soul." That which first takes strongest hold in the soul cannot be oriented to by the child because it infiltrates the soul before he has the capacity to decide upon it. By what means is the appetite for coordination established?

Music is a metaphor for the indefensible influence of social structure which is embodied in the soul. To say that "rhythm and harmony seek deep into the recesses of the soul" is to say that the first fact of life for the child is being oriented to in a way which exemplifies the rhythm and harmony of the whole (in a way which exemplifies the desirability of order). Thus, what takes first hold on the child is the way in which power is embodied in the environment. Music suggests the primordial influence of proportion upon the soul: that the child orients to that which orients to him and so, begins by needing and desiring to emulate the interest taken in him by reproducing it as an interest in himself. Music references that embodiment as the "grace of body and mind" of the harmonious and rhythmic influence. The first writing on the soul-the writing that is permanently inscribedis the opportunity for exemplary influence (music) which is expressed in the welcome given to the child by the whole. We must be able to understand how the child needs to formulate his first experience as a welcome which he is given. This is to say that the first need of the child is to find discrimination both necessary and pleasing.

The first need of the child is to orient to that which acts upon him. We say that the child needs to discriminate order from disorder and so he needs to welcome that which helps him to achieve order rather than disorder. The "music" metaphor expresses the sense that the child is never completed in the family, but rather prepared well or poorly to discriminate between the conditions to which he is exposed. This preparation means that the child is attached to order through the body, through the development in him of an instinct for order that is only possible through his having embodied the desire for pleasure as the desire for order. This is the strength of music as the first writing: it expresses how what is desired as pleasing must be embodied as (beauty) order and how what is created as painful must be embodied as (ugliness) disorder. The notions of order and disorder introduce rightness or ethics to pleasure by insuring that what is pleasing is treated as right.

A good upbringing is said to establish "grace and elegance." What this means is that the child will treat his unqualifiedness positively as a need 
for coordination of body and mind. He will seek to embody in his soul images of rhythm and harmony. The result of the first writing is to establish in the child a desire for coordination, a need to show an interest in reproducing orderliness as a pleasing relation within his soul.

That the child is unqualified says that he is essentially awkward. The first writing arouses him to his awkwardness less as distress than as an incentive to coordinate a pleasing relation (elegant, grace) within the soul. Elegance and grace express the way in which the child shows an interest in embodying the need for order as the pleasure of a coordinated soul (body and soul).

\section{The Rightness of Order}

Let us ask how this notion of rightness so necessary to rescue the idea of pleasure from its identification with replenishment is embodied in a recognition of needing something secure (orderly) rather than variable (dispersive). We have said that this is reflected in the need for order as the need for a well-ordered soul. The child orients to his own development by being hospitable to the idea of a well-ordered soul and by his being repulsed by the prospect of a dispersive soul. The discriminating child treats the prospect of his developing a well-ordered soul as both necessary and pleasing. The need for self-governance reflects the child's need to be hospitable to the prospect of a well-ordered soul as an end that is necessary and desirable in itself.

Think of the school as demanding - only those who have recognized the need to examine the rightness of what gives them satisfaction should enter. Now, we understand that as requiring the recognition of the need for a well-ordered soul. We might be satisfied to judge the finger before us a finger. But when we confront the notion-such as the notion of society, of social class, of unity, of race-we have an opportunity to reflect upon whether what appears to us as satisfying and familiar is a good or right example of what the notion is.

Because mathematics introduces us to the possibility that what our judgement discloses $\mathrm{X}$ to be does not have to be, it opens us to the question of necessity in the form of possibility: it exposes us to the question of the relation between the judgement of the thing and the possibility of the thing as given through an examination of the notion in-itself.

Mathematics raises the question of whether our satisfaction is spurious because it compels us to deliberate upon the correspondence between the requirements of the notion and our own judgement that the notion has been realized to our satisfaction. The well-ordered soul is exemplified by the one who deliberates upon the question of how the appearance of $\mathrm{X}$ is a good example of what is.

What is said here must be heard carefully: to examine the rightness of what gives satisfaction does not mean to engage in dialectic. Rather, it means that our satisfaction with our judgement needs to be recognized as guided by some expectation concerning the rightness of what our judgement judges. 
The academy then asks its students to see the need to produce whatever the expectations expect of them as a need integral to their development. The academy does not ask its students to be conformist: only that they see the need for compliance to be oriented. The study of mathematics arouses the child to orient his judgements of sense to something other than distress or replenishment but to an interest in pleasing the standard as if it was his own pleasure.

Mathematics says-only in giving pleasure to the standard do you please yourself. Mathematics opens the door to a recognition of the need to integrate self and other-to true sociality - for it requires the young to require of themselves the pleasure that comes from pleasing the standard.

We say that mathematics creates the opportunity for true sociality in this sense: that compliance to the standard that is not pleasing creates unendurable, obligatory loyalty and satisfaction that does not orient to pleasing the standard does not have a sense of how what it judges as satisfying is truly, rather than apparently, pleasing.

So the sign above the academy door warns-only those who have conquered the temptation of the split life should enter!

Now the question is-how does a good upbringing fortify the child by arousing him to see the need to overcome the split life?

\section{Desire for the Notion}

Recall Socrates saying that the child needs to be exposed to the contradiction inherent in the notion. Socrates' example is the idea of unity, that one can be many and many can be one.

If unity can be satisfactorily apprehended, just by itself, by sight or any other sense as we say of the finger, then it will not have the quality of drawing the mind towards reality. But if it is always seen in some contradictory combination, so as to appear no more one than the opposite of one, then a judge will be needed to decide: the mind will be forced to seek a way out of the difficulty, setting thought in motion and asking what unity means.

Well, unity is a case in which sight does present a contradiction. We see the same thing as both one and also indefinitely many.

Then, if it is true of unity, all number has the same property, hasn't it?'

"Number" is the Greek way of speaking about the notion (as Hegel would say). The notion, whether "unity," "mathematics," "man," or "upbringing," presents an inherent contradiction. That we see the same notion as both one and many does not refer to a limitation of perspective but to the fact that language enables us to understand, e.g., the notion of "Socrates," as both the oneness which that name comprehends and limits and the manyness of the various embodiments of that name which we collect as "Socrates." What is true of unity as an example is true of all number, it is true of speech.

The child has to be provoked to see how number-the word, the notion -always needs something other; the notion always introduces the question of how it is a one and a many. 
It is as if mathematics introduces the need to qualify the limits of counting, of arithmetic, of the word, of the notion, by pointing to how it is part of the whole. As Wittgenstein says, mathematics exposes the dependency of the notion upon its grammar or logic. What this means is that the very resonance of the notion "forces" us to "set our thought in motion" by asking what the notion means.

What we are saying then is simply this: that the period of mathematics is the period when the child is provoked to ask after the meaning of the notion. The well-ordered soul is the soul that seeks to deliberate upon the question of the orderliness of the notion.

We say that mathematics introduces the sense of limitation that challenges us to see the need to think out of context. It is the first recognition that pleasure does not have to be situated in one context, for the recognition that the notion is both a one and a many shows how its applications or uses are many, are multitudinous. If this shows us the freedom in usage, it still binds us to the recognition that a notion like, e.g., "Socrates," is not arbitrary, that it has substance or content which requires us to heed what it could say. (For example, if there is freedom in the usage of "social class," we still do not invent just anything to stand for what "social class" is.)

Mathematics introduces the offspring to language in the sense that it shows him how the notion has requirements of its own and that his satisfaction must be oriented to the need to give satisfaction to those requirements.

The notion, then, has possibilities that are not exhausted in any one appearance and the child's introduction to the possibility of possibilities means that his satisfaction now has to be governed by the need to be responsive to the demand which the question of possibility releases.

The appearance of the notion always gives us the opportunity to treat the relationship of how it appears to what it means as a problem. We do this by questioning after the relation between what the notion is reputed to mean (what it appears to be) and what it could mean.

The interest in grammar or logic that mathematics stimulates is an interest in asking what the notion could mean: it reflects an interest in asking after the possible.

So the sign says--let only those who have learned to ask after the possible-let only those who have been exercised by the difference between what is reputed to be and what could be-let only those enter.

My boy, if anyone means to deliberate successfully about anything, there is one thing he must do at the outset: he must know what it is he is deliberating about; otherwise he is bound to go utterly astray. Now most people fail to realize that they don't know what this or that really is: consequently when they start discussing something, they dispense with any agreed definition, assuming that they know the thing; then later on they naturally find, to their cost, that they agree neither with each other nor with themselves. ${ }^{\text {? }}$

In this passage from the Phaedrus, Socrates begins to formulate conversation as a practice that must take its bearing from the question $t i$ estin; otherwise, he maintains, it would be bound to go utterly astray. 
Many assume that they know what-it-is they are discussing because they have a sense of the topic or an opinion on the matter at hand; they defer the question concerning identity only to discover after some time has passed that they not only differ from one another but from themselves as well. So overwhelming is the dissonance that prevails when speech defers the search for a difference, different than the differences between speeches, that many can hardly remember how the conversation began or where it should conclude. Let the one who has tired of wandering take his bearing from the question "What is to ti-estin?" The well ordered soul is the tendency to become engaged by the question of the mathematical which is aroused by the contradiction: the well-ordered soul sees the need to ask $t i$ estin of the notion.

The unqualifiedness of the child exists as his recognition of the need for coordination, as a need which materializes in his capacity to ask ti-estin? The need to ask ti-estin-the what is it? presupposes that he has been sheltered from the charms of multis to the point where he craves the "grace and elegance" (the coordination) expressed in the question. The question ti-estin? presupposes that he has taste, the power to discriminate, because he can see that the question is what is needed. What is needed is to gather to the notion what essentially belongs to it as its identity; $t i$-estin expresses the way in which his development of what implicitly and essentially belongs to the notion is needed by him for his own development of what he is implicitly and essentially as a well-ordered soul. He sees the need to express his own collectedness through his development of the notion.

If his desire for pleasure is expressed as the need for order, the need itself must be embodied in practices: the connection between the pleasant and the orderly is supplied by speech. His desire for the pleasant, i.e., wellordered soul, is expressed as the desire for well-ordered discourse, i.e., in his need to develop the identity of the notion. And his taking pleasure in the development of the notion is embodied as his enjoyment with the orderliness of his soul.

In this sense, we say that Paideia expresses the era of mathematics in the soul since this is what the desire for order references. First, music and then discourse appear as examples of how to establish the pleasing character of order. In discourse, order itself is referenced by the interest in $T i$ estin and the pleasure which comes from asking this question.

Ti-estin symbolizes the embodiment of the desire for pleasure as an appetite for order at the level of discourse. It is distinguished from music only technically; analytically, it is another expression of the need to establish for the child the necessary identity of the pleasing and the orderly.

If the primordial writing identifies discourse with music, this only means that order itself must be desired as pleasing. Music is a condition rather than a limit for it is first necessary to equate the pleasing and the orderly (to be exposed to music) before an examination of the orderly can occur.

To examine the orderly is to be free of the need to struggle to achieve the identification of pleasure and order: it is to be able to stand fast on the ground of this identity so as to ask how the order that is desired is 
collected, limited and constituted. Ti-estin? expresses the strong sense of music as such a condition, for the one who asks, Ti-estin? has already learned mathematics. In other words, he knows and is secure with the understanding that order (beauty) is pleasing, and so he does not have to re-enact that struggle.

But why then is mathematics insufficient? Why is it a condition for entering the academy? That is, if the family arouses us to mathematics and if mathematics is good, i.e., provocative, then why do we need the school? There is a hint in the following remark of Socrates:

geometry and those allied studies ... do in some measure apprehend reality; but we observe that they can not yield anything clearer than a dream-like vision of the real so long that they leave the assumptions they employ unquestioned and give no account of them. ${ }^{8}$

This is to say that asking after the possible is the beginning but not the end. What is required is to see the deeper contradiction between what is possible and what is right. For example, if to do what is possible for the child requires more imagination than merely doing what is absolutely and minimally required, doing what is possible is not necessarily doing what is right. Mathematics has its limits. The possible is not the right without demonstration.

The child's exposure to mathematics cannot terminate his development because this very exposure needs to awaken in him the desire for demonstration, i.e., for a deliberation upon the goodness of the possible.

To resituate this discussion as a history of the soul: the child's identification of the pleasing and the satisfying recedes under the impetus of frustration when he sees that what he judges satisfying is only an apparent rather than a true pleasure.

He comes to be pleased not by what previously satisfied him but by the promise of grasping the possibility of the notion-its essential and intrinsic orderliness-as this is embodied in discourse as the difference between what appears to be and what is. To grasp the possibility of the notion is pleasing insofar as the interest in the relation of what appears to be, to what is, stresses an interest in order per se and an aversion to disorder.

Real contradiction which signals the need for school-for dialecticthen emerges insofar as his recognition of the desirability of order over disorder promises to renew his frustration leaving him speechless in the face of this difference (this is the period we think of as adolescence). $\mathrm{He}$ is speechless because the desire to disclose the possible "yields only a dreamlike vision of the real" so long as it shows no interest in demonstration. The need for demonstration references the need to realize the possible as what is right.

The need for demonstration is the need to embody in one's soul a sense of the necessity and desirability of what is possible as one's own: it references the need to show one's self the rightness of what is needed. Socrates speaks of taking oneself through the steps of a proof; what he means is that the notion's need for self-development must be integrated with our own need for demonstration. 


\section{Notes}

1. This is the way in which René Girard has come to formulate Desire in his various works, especially Deceit, Desire, and the Novel, the Johns Hopkins University Press, 1965.

2. The Republic, Cornford translation, p. 238, vii, 523.

3. See particularly, Wittgenstein's On Certainty, and the interesting study on this in Morawetz, 1978.

4. Note that this can happen only through satisfaction. What is good or necessary about satisfaction is that it provides for its own development.

5. The Republic, p. 90, III, 401.

6. The Republic, p. 241 , vii, 524 .

7. Phaedrus, 237c.

8. The Republic, p. 253. vii, 533.

\section{References}

Girard, R. (1965). Deceit, Desire, and the Novel. The Johns Hopkins University Press. Morawetz, T. (1978). Wittgenstein and Knowledge, Boston: University of Massachusetts Press. 